\title{
EFFECTS OF EMPLOYEES' POSITIVE AFFECTIVE DISPLAYS ON CUSTOMER LOYALTY INTENTIONS: AN EMOTIONS-AS- SOCIAL-INFORMATION PERSPECTIVE
}

\author{
ZE WANG \\ University of Central Florida \\ SURENDRA N. SINGH \\ University of Kansas \\ YEXIN JESSICA LI \\ University of Kansas \\ SANJAY MISHRA \\ University of Kansas \\ MAUREEN AMBROSE \\ University of Central Florida \\ MONICA BIERNAT \\ University of Kansas
}

\begin{abstract}
Employees' positive affective displays have been widely used as a strategic tool to enhance service experience and strengthen customer relationships. Companies have primarily focused their employee training programs on two dimensions of display: intensity and authenticity. Yet there is limited research on when, how, and why these two dimensions affect customer reactions. Drawing on the emotions as social information (EASI) framework (Van Kleef, 2009), we develop a conceptual model in which display intensity and display authenticity differentially influence customer loyalty by changing customers' affective reactions and cognitive appraisals. Further, we propose that the relative impact of either dimension depends on customers' motivation to understand the environment deeply and accurately (i.e., their epistemic motivation). We tested our model in one field study and one laboratory study. Results across these two studies provide consistent support for the proposed model and advance our understanding about how different dimensions of employees' positive affective displays enhance customer reactions. Thus, findings of this research contribute to knowledge on the interpersonal effects of emotions in customer-employee interactions.
\end{abstract}

We call these traits 'The Core Four'-eye contact, speaking enthusiastically, smiling, and engaging the customer.

\section{- Ronnie Clotfelter, owner and operator of Chick-fil-A, Sharpsburg, Georgia}

Focus on winning one customer at a time. Be honest and sincere.

We are grateful to associate editor Gerben Van der Vegt and three anonymous reviewers for their extremely helpful guidance throughout the review process. We also thank our research assistants for their earnest efforts.
- Robert Spector, The Nordstrom Way to Customer Service Excellence

In many services, employees' displayed emotions toward customers are crucial determinants of customer satisfaction and loyalty. Policy statements exemplified by the two quotes above demonstrate the importance of employees' affective displays, as well as the fact that they are trained to emphasize different dimensions of display. Some employees are obliged to follow scripted requirements, which demand that positive emotions be displayed frequently during customer interactions, regardless of whether 
the emotions are authentically felt (Pugh, 2001; Rafaeli \& Sutton, 1990). Others, however, are trained to focus on authenticity rather than intensity, e.g., "be honest and sincere" (the Nordstrom Way) and apply "the principles of trust, honesty, respect, integrity, and commitment” (Ritz-Carlton Gold Standards).

Policies that emphasize authenticity differ from those that highlight intensity in critical ways, including time and financial commitments on the part of the company and employees (Hochschild, 1983; Richard, 2006). When making important decisions about display policies, managers should have a good grasp of which dimension of affective display is best for their needs. For instance, what type of customer responds more favorably to intense positive expressions than to authentic displays? How and why do these dimensions of employees' displayed emotions (intensity and authenticity) impact customer responses in service deliveries?

The research reported here is designed to address these questions and provide a better understanding of when, how, and why the intensity and authenticity of employees' displayed emotions differentially impact customer responses in service deliveries. To this end, we draw on the emotions as social information (EASI) model (Van Kleef, 2009) to simultaneously examine the influence of display authenticity and display intensity in customer-employee interactions. We contend that: (a) these two dimensions influence customer responses through different mechanisms (emotions, cognitions); and (b) customers' epistemic motivation, or the motivation to develop and maintain a rich and accurate understanding of one's current situation (Kruglanski, 1989; Van Kleef, De Dreu, \& Manstead, 2004), alters the effect of employees' display intensity and authenticity on customer responses. We develop and test a moderated mediation model in which display intensity and display authenticity influence customer loyalty through their effects on customers' psychological responses, and these indirect effects are moderated by epistemic motivation.

This research extends the extant literature on the role of employees' displayed emotion in service deliveries. Despite the importance of employees' positive affective displays, prior research has not fully addressed what we need to know about customers' reactions to different dimensions of emotional display (Groth, Hennig-Thurau, \& Walsh, 2009). Researchers have recognized the importance of intensity and authenticity (Barger \& Grandey, 2006; Grandey, Fisk, Mattila, Jansen, \& Sideman, 2005; Pugh, 2001; Wang \& Groth, 2014), but these facets have typically been studied separately. This is problematic, for emotional displays vary along both dimensions and the unmeasured dimension may contribute or even drive the obtained effects. The only study (Hennig-Thurau, Groth, Paul, \& Gremler, 2006) that simultaneously examined the effects of intensity and authenticity on customer reactions found that the effectiveness of employees' emotional labor depends on authenticity but not intensity, raising the questions of whether intensity has any unique effects on customer reactions and whether these findings would hold in different contexts. We argue that both intensity and authenticity play a role in customer reactions, but their influence depends on the customer's motivation to process information. In the current research, we consider intensity and authenticity simultaneously, explore the mechanisms that underlie their influence on customer reactions, and illustrate moderating factors that alter their effectiveness. We provide answers to previously unexplored questions such as: which customers respond favorably to intense versus authentic positive displays, and why? What guidelines should managers use when determining whether to emphasize intensity or authenticity in employee training programs?

This research also contributes to the literature on the EASI model. Previous studies using this model have so far examined discrete emotions such as anger (Van Kleef, Anastasopoulou, \& Nijstad, 2010), happiness (Van Kleef et al., 2004), disappointment and regret (Van Kleef, De Dreu, \& Manstead, 2006) (see Van Kleef et al., 2010 for a recent review). Drawing on the EASI model, this research compares two expressive dimensions of the same emotion (happiness): intensity and authenticity. We contend that these dimensions offer nuanced information about the expresser, and that receivers selectively use this information to determine how to react. Moving beyond valence-based effects as well as the differential impact of discrete emotions, we propose that different dimensions of the same emotion provide functional information that is relevant to social coordination and interaction.

This study is also the first attempt to test the EASI model in the context of employee-customer interactions. Previously, the EASI model has largely been limited to experimental studies on conflict and negotiation (De Dreu \&Van Kleef, 2004), leadership and team performance (Van Kleef et al., 2010), and ongoing personal relationships (Martini \& Busseri, 2012). In such relationships, the outcomes of the expresser and perceiver are heavily intertwined. By examining the tenets of the EASI model in the employee-customer domain, we test the applicability 
of the model to situations in which the expresser and receiver do not necessarily share outcomes or have a lasting relationship with each other. Extending the EASI model to these situations is important because previous research has found that qualitatively different types of relationships have their own decisionrules and interaction norms (Fiske, 1992).

Our findings also have important practical implications. Organizations train, monitor, and manage their frontline employees' positive affective displays very carefully (Grandey, 2003). These practices consume a significant portion of spending on employee learning and development (Richard, 2006), which was estimated at a staggering $\$ 164.2$ billion in 2012 in the United States alone (ASTD, 2013). But it is not always clear what kind of affective display is most effective. Our research provides a framework for companies to understand how and why the effectiveness of employees' positive affective displays may differ depending on the customers' or recipients' characteristics.

Below, we develop an EASI-based model for examining the relationship between employees' positive affective displays and customer loyalty. We begin with an overview of research on displayed emotion, followed by a description of the EASI model and its relevance to research on emotional displays. We test our hypotheses in both a field study and a laboratory experiment. Theoretical and practical implications of the findings are discussed.

\section{THEORETICAL DEVELOPMENT AND HYPOTHESES}

\section{Dimensions of Positive Affective Displays: Intensity and Authenticity}

Prior research on employees' displayed emotions has concentrated primarily on positive affective displays or employees' expression of socially desired emotions in customer interactions (e.g., Pugh, 2001; Rafaeli \& Sutton, 1990). This is also the focus of our investigation. We examine two dimensions of display: intensity and authenticity. The intensity of emotional displays refers to mechanical aspects, such as the strength and frequency of smiling (Barger \& Grandey, 2006), or the aggregated occurrence of positive display behaviors, such as establishing eye contact, greeting the customer, and changing intonation (Tsai \& Huang, 2002). The stronger or more frequent these behaviors, the more intense the display. Studies that highlight the importance of the intensity of employees' display find that frequent positive emotional expressions, such as broad smiles, greetings, and frequent eye contact typically elicit positive customer outcomes (e.g., Barger \& Grandey, 2006; Pugh, 2001).

The authenticity of emotional displays, on the other hand, reflects the extent to which employees' expressions are consistent with their internal affective states (Grandey, 2003). Authenticity can be viewed from two perspectives: the actor's and the observer's. From the actor's perspective, "emotional authenticity refers to a person's ability to acknowledge, express, and be sincere about his or her feelings" (Huy, 1999: 339). In the current research, we are interested in the observer's perception of authenticity. Since the observer is not privy to the actor's internal feelings, authenticity from his/her viewpoint refers to the extent to which the actor appears to be expressing his/her true emotions versus attempting to "mislead another person into thinking an emotion is felt when it is not" (Ekman, 1993: 390). Prior research has found that perceivers can recognize sincere from fake emotional expressions (Ekman \& Friesen, 1982; Ekman, O'Sullivan, \& Frank, 1999) and generally respond more positively to authentic (versus inauthentic) displays due to the importance of honesty and trustworthiness in social interactions (Hennig-Thurau et al., 2006). In support of this, studies that stress the importance of authenticity have found that employees' deep (versus surface) acting, which results in more authentic affective displays, generally leads to more positive customer reactions, such as satisfaction, rapport, and loyalty intentions (e.g., Grandey et al., 2005; Groth et al., 2009).

Although extant research has provided important insights on emotional displays, there are some gaps in our knowledge. For example, researchers have typically examined either intensity or authenticity; they have rarely considered the two simultaneously. Because positive expressions usually vary in both intensity and authenticity, there may be possible confounds inherent in focusing on a single dimension (e.g., the unmeasured facet may contribute to or even drive the observed effects). In addition, it is unclear whether contexts that reduce or enhance the effectiveness of one dimension produce similar effects on the other dimension. In other words, the question of what kind of customers and services respond best to authentic versus intense displays remains unanswered. The broader research literature on emotions demonstrates that how observers process emotions and respond to them depends on a predictable set of individual and situational characteristics (Van Kleef, 2009). Building on this work, 
we argue that customers' motivation to thoroughly understand their environment will influence how display intensity and display authenticity affect customer responses.

\section{The Emotions as Social Information Model: Two Paths to Emotional Influence}

Research on workplace emotions has increased in the last decade. Much of this research has focused on the intrapersonal effects of emotions. However, emotions are not simply reflections of one's internal affective states; they are also social informational cues that communicate important messages to observers, e.g., the displayer's personality or interpersonal intentions (Fridlund, 1992). The EASI model provides a comprehensive framework to understand how emotional expressions are interpreted and used by observers (Van Kleef, 2009). This model proposes that emotional expressions can affect observers' behaviors via two distinct routes: (1) affective reactions and (2) cognitive appraisals.

Affective reactions refer to the emotions elicited in the observer. They generally arise when the displayer's emotional expression elicits corresponding emotions in the observer through primitive contagion (e.g., Hatfield, Cacioppo, \& Rapson, 1992; Pugh, 2001). Primitive emotional contagion or "catching" another's emotions (Hatfield et al., 1992) occurs spontaneously and requires relatively little cognitive processing. Cognitive appraisals, on the other hand, are inferences that an individual draws about the expresser's true feelings and intentions. Unlike affective reactions, cognitive appraisals require observers to make inferences about the meaning of the expresser's emotional displays, which guide attitudes and behaviors by providing contextually relevant information about the expresser.

Critically, the EASI model stipulates that the extent to which an observer is influenced by affective reactions and cognitive appraisals is determined by his/her epistemic motivation. Epistemic motivation refers to how motivated the observer is to understand the environment deeply and accurately (Kruglanski, 1989; Van Kleef et al., 2004). Observers with high epistemic motivation are more likely to pay attention and use all available information before making a decision, and thus are more susceptible to the influence of cognitive appraisals (Van Kleef, Homan, Beersma, Van Knippenerg, Van Knippenberg, \& Damen, 2009). Observers with low epistemic motivation, on the other hand, have been shown to be more likely to rely on their feelings when making judgments (Albarracin \& Wyer, 2001) and should thus be more influenced by their affective reactions.

Prior research using the EASI model has investigated the impact of discrete emotions (e.g., sadness versus happiness) on these two routes of influence (Van Kleef et al., 2010). Research on emotional labor and affective displays, however, suggests that one emotion can be comprised of several distinct dimensions (Grandey et al., 2005; Hennig-Thurau et al., 2006). We thus extend the existing EASI literature by investigating how two dimensions of the same emotion-intensity and authenticity-differentially affect affective reactions and cognitive appraisals to influence customer attitudes and behaviors. We suggest intensity influences customer reactions through the affective route, whereas authenticity influences customer reactions through the cognitive route. As we explain in more detail later, this assertion is based on reasoning and evidence that intense displays of positive affect influence customer reactions mainly through emotional contagion, while authentic displays of positive affect influence customer reactions through processing of the emotion's meaning. Additionally, in line with the EASI model, we propose that the effect of intensity and authenticity on customers' responses is determined by the customer's epistemic motivation. The conceptual framework of the current research is presented in Figure 1.

\section{Display Intensity and Customers' Affective Reactions}

The first route by which emotional displays influence customer reactions is the affective route. Prior work on display intensity suggests employees' intense positive displays, such as broad smiles, greeting, intonation, and frequent eye contact, influence customer outcomes by changing or enhancing customer emotions (Pugh, 2001). To explain this effect, several streams of intensity research have utilized emotional contagion theory (Hatfield et al., 1992). Emotional contagion theory contends that humans innately and unconsciously mimic the nonverbal behaviors of others and, in doing so, converge emotionally with them through physiological feedback (Laird \& Bresler, 1992). Hatfield, Rapson, and Le (2009: 26) provide a description of how emotional contagion operates:

In theory, the process of emotional contagion consists of three stages: Mimicry, Feedback, and Contagion. People tend: (a) to automatically mimic the facial expressions, vocal expressions, postures, and instrumental 
FIGURE 1

A Conceptual Model of Customers' Responses to Employees' Positive Affective Displays in Service Encounters

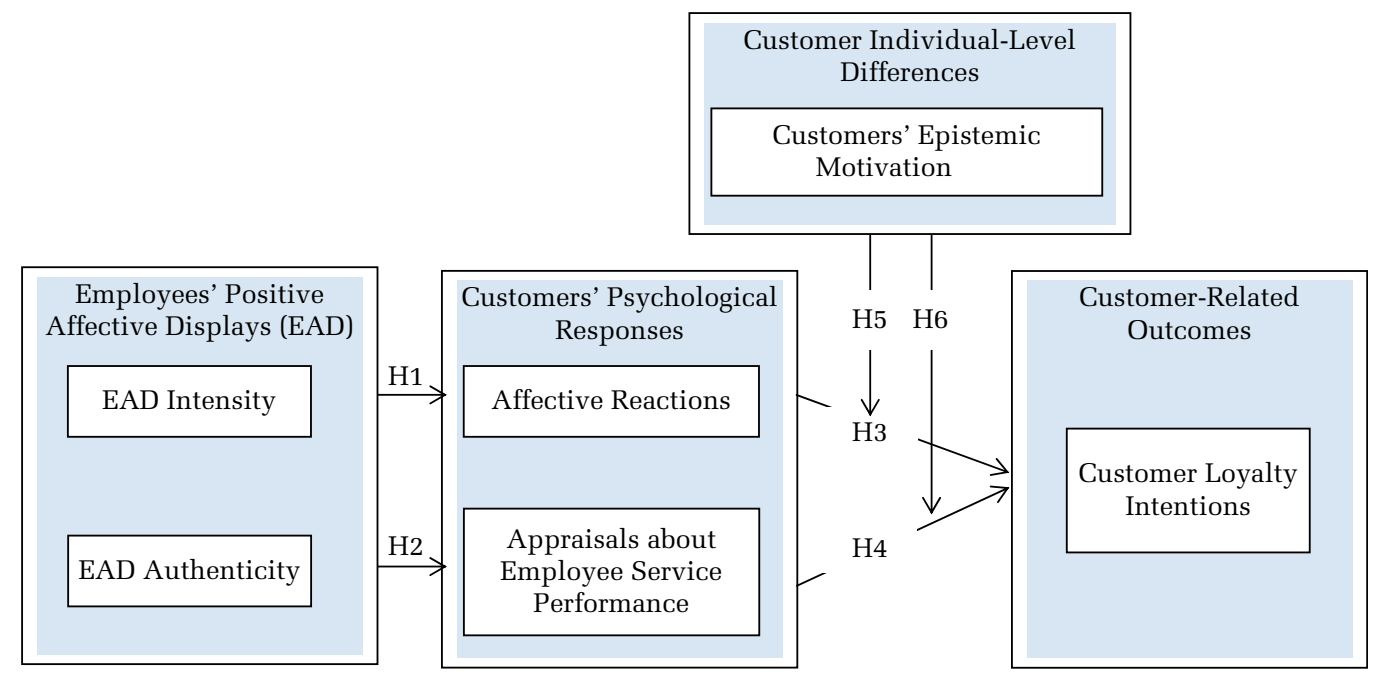

behaviors of those around them, and thereby (b) to feel a pale reflection of others' emotions as a consequence of such feedback. (c) The result is that people tend to catch one another's emotions.

Presumably, when people automatically mimic their companions' fleeting facial, vocal, and postural expressions of emotion, they often come to feel a pale reflection of their companions' actual emotions. By attending to this stream of tiny moment-to-moment reactions, people are able to "feel themselves into" the emotional lives of others.

We posit that observers are more likely to pick up on and thus successfully mimic behaviors that are more intense or frequent, a prediction that is supported by previous research (Barger \& Grandey, 2006; Pugh, 2001; Tsai \& Huang, 2002). Barger and Grandey (2006), for instance, find that employees' smile strength (a common measure of intensity) predicts customers' smile strength, which enhances customers' positive mood. Importantly, even fake displays of positive emotions in the expresser may engender positive emotions in the observer. In a field test involving service interactions between 220 customers and 191 bank tellers, Pugh (2001) found that intense positive affective displays in employees increased customers' positive affect, but that these emotional displays were not significantly related to employees' internal feelings, leading to the suggestion that "A professional acts as they must, not as they feel" (Pugh, 2001: 1018). Based on the aforementioned research, we propose that display intensity affects observers primarily through spontaneous contagion processes that result in emotional convergence with the displayer:

Hypothesis 1. The intensity of employees' positive affective displays will produce positive affective reactions in customers.

\section{Display Authenticity and Customers' Cognitive Appraisals}

The second route identified in the EASI model is through cognitive appraisals. Observers make contextspecific cognitive inferences from an expresser's affective display that provide relevant information about the situation or the expresser, such as whether he/she wants to affiliate (displays a smile) or be left alone (displays a frown) (Van Kleef, 2009). Consistent with the EASI model, research suggests that observers derive meaning from the authenticity of affective displays (Van Kleef, 2009; Wang \& Groth, 2014). Display authenticity may be an especially important cue from which to make judgments about the expresser because it provides information about his/her personality and intentions (Ekman, Friesen, \& O'Sullivan, 1988). In general, an authentic smile conveys that the expresser is trustworthy, kind, sociable, and cooperative, while an inauthentic smile signals that the expresser is putting on a "mask" because of social norms or as an attempt to deceive the observer (Krumhuber, Manstead, Cosker, Marshall, Rosin, \& Kappas, 2007).

In the context of service delivery, the relevant cognitive appraisals customers make are about 
employee service performance (Gabriel, Acosta, \& Grandey, 2013), or the degree to which employees successfully perform "behaviors that are relevant to organizational goals and that are under the control of individual employees" (Liao \& Chuang, 2007: 42). Employee service performance encompasses factors such as the extent to which the employee is trustworthy, cares about customers' needs, and is willing and able to provide service (Brady \& Cronin, 2001).

We propose that the authenticity of employees' positive displays influences customers' appraisals of employee service performance in several ways. First, authenticity is related to trustworthiness, a main component of service performance. Second, employees' authentically positive displays signal their motivation to move beyond the "required" role and that there is genuine intention to be helpful to customers (Grandey et al., 2005). This enhances customers' perceptions of the employee as customerfocused, and results in more favorable evaluations (Chi, Grandey, Diamond, \& Krimmel, 2011; Groth et al., 2009). Inauthentic emotional displays, on the other hand, can be interpreted as a lack of interest in developing a close relationship with the customer or evidence that the employee is not trustworthy (Coté, 2005; Grandey et al., 2005), leading customers to infer that the employee is unwilling or unable to provide a quality interaction. In sum, we hypothesize that authentic (versus inauthentic) affective displays will lead to positive appraisals about employee service performance.

Hypothesis 2. The authenticity of employees' positive affective displays will lead customers to make positive appraisals of employee service performance.

\section{Effect of Affective Reactions and Cognitive Appraisals on Customer Loyalty Intentions}

While eliciting positive mood and appraisals in customers is desirable, this is often not the end goal for managers and organizations. The hope is that positive mood and appraisals lead to downstream consequences such as customer loyalty. Customer loyalty is a behavioral construct that is influenced by customers' feelings of attachment and affection toward an organization (Payne \& Webber, 2006). Loyalty intentions are demonstrated through customers' intentions to continue business relations or to spread positive word-of-mouth (Swan \& Oliver, 1989). Customer loyalty is a strong predictor of organizational profit and growth (Reichheld \& Teal, 2001; Rust \& Zahorik, 1993).
Customers' positive affective reactions can enhance loyalty intentions in several ways. When individuals are in a positive mood, they tend to look at the world through rose-colored glasses and make global positive evaluations (Sinclair, 1988). In addition, people generally strive for positive experiences and seek encounters that have induced positive emotions in the past (Skinner, 1953). Indeed, customers who experience more positive feelings during a service transaction are more likely to stay longer in a store (Tsai \& Huang, 2002), spread positive word-of-mouth (Swan \& Oliver, 1989), and express higher intentions to revisit the store (Hennig-Thurau et al., 2006). These findings lead to the following hypothesis:

Hypothesis 3. Positive affective reactions positively relate to customer loyalty intentions.

Positive appraisals of employee service performance have also been shown to affect customer loyalty intentions (Salanova, Agut, \& Peiró, 2005). When frontline employees extend their respect and courtesy to customers, they help the firm form a bond with customers, which leads to more favorable evaluations of the service experience (Keh, Ren, Hill, \& Li, 2013). Furthermore, customers' perception of employees' congenial attitudes and behaviors drive customers' intentions to stay loyal to a firm (Liao \& Chuang, 2007; Payne \& Webber, 2006; Salanova et al., 2005). A survey of 2,170,004 patients from 1,506 hospitals, for example, found that employee service performance (as measured by responsiveness to customers' concerns and complaints and sensitivity to the inconvenience of medical service) was highly correlated with patients/customers' likelihood of recommending the hospital to others (Berry, Wall, \& Carbone, 2006). This leads us to predict:

Hypothesis 4. Positive appraisals of employee service performance positively relate to customer loyalty intentions.

\section{The Moderating Role of Customers' Epistemic Motivation}

Thus far, we have argued that the intensity and authenticity of employees' affective displays influence customers' affective reactions and cognitive appraisals, respectively, which in turn affect loyalty intentions. Although both affective reactions and cognitive appraisals can lead to greater loyalty intentions, it is theoretically and managerially important to determine when each process is likely to 
produce positive outcomes. According to the EASI model, the impact of these two processes is determined by the observer's epistemic motivation (Kruglanski, 1989; Van Kleef et al., 2004). Epistemic motivation is an individual's motivation to develop a rich and accurate understanding of one's current situation. It is strongly tied to information processing style. Heightened epistemic motivation has been linked to focused search of diagnostic information (Kruglanski \& Webster, 1996), decreased use of heuristics and stereotypes (Fiske \& Neuberg, 1990), and increased systematic processing (Mayseless \& Kruglanski, 1987).

Prior research has determined that heightened epistemic motivation accentuates the effect of cognitive appraisals and attenuates the influence of affective reactions. In a study of leader emotions on follower performance, Van Kleef et al. (2009) found that followers who had high epistemic motivation were heavily influenced by their cognitive inferences of the leader's emotions, while those who had low epistemic motivation were more influenced by their affective reactions to the leader's emotions. Van Kleef et al. (2009) suggest this is because low epistemic motivation leads individuals to base their behavior on their emotions, whereas high epistemic motivation leads individuals to "rely less on their affective state but instead use other sources of information to guide their behavior, such as information provided by others' emotional displays" (p. 565). Similarly, other research has shown that while emotions are easily accessible heuristic guides, individuals with high epistemic motivation are more likely to discount their affective reactions as inaccurate or irrelevant, leading them to rely more on cognitive appraisals (Albarracin \& Kumkale, 2003; Greifeneder \& Bless, 2007).

The EASI model thus suggests that the influence of emotional display intensity on customer loyalty intentions via affective reactions will be accentuated as customers' epistemic motivation decreases, whereas the impact of emotional display authenticity on customer loyalty intentions via cognitive appraisals will be enhanced as customers' epistemic motivation increases. Formally, we hypothesize:

Hypothesis 5. Customers' epistemic motivation moderates the relationship between the intensity of employees' positive affective displays and customer loyalty intentions through customers' affective reactions, such that the mediated relationship is weakened when customers have higher levels of epistemic motivation.
Hypothesis 6. Customers' epistemic motivation moderates the relationship between the authenticity of employees' positive affective displays and customer loyalty intentions through customers' appraisals about employee service performance, such that the mediated relationship is strengthened when customers have higher levels of epistemic motivation.

We test the proposed hypotheses in two studies. In Study 1, a field study, we examine the effects of employees' intensity and authenticity on customer loyalty intentions through affective reactions and appraisals about employee service performance, and investigate the moderating role of self-reported motivation to process the employee's behavior. Study 2 provides a replication of Study 1, using a better controlled videosimulation methodology and a more established individual difference measure of epistemic motivation.

\section{STUDY 1: FIELD STUDY WITH IN-SITU OBSERVATIONS AND SURVEYS}

In this field study, we examine the proposition that two dimensions of employees' displayed emotions (intensity versus authenticity) differentially impact customers' responses, and that customers' epistemic motivation moderates these effects. The current research focuses on customers' reactions to employees' affective displays. Therefore, Study 1 investigates the moderating role of one specific type of epistemic motivation-customers' motivation to develop an accurate understanding of employees' displayed emotions (Coté \& Hideg, 2011), which should determine the relative influence of affective reactions and cognitive appraisals on loyalty intentions. According to the EASI model (Van Kleef, 2009), customers are more likely to base their behavioral intentions on their emotions when they have low (versus high) epistemic motivation. Therefore, the effects of affective display intensity on customer outcomes via affective reactions should be stronger when epistemic motivation is low. On the other hand, the effect of authenticity via cognitive appraisals should increase as epistemic motivation increases.

\section{Procedure}

In this study, we observed customer-employee dyadic interactions in 36 stores, which represent a variety of services, such as fashion retailers, dining services, and grocery stores. The first author trained five research assistants for two weeks by using 
relevant literature on emotion detection (e.g., Ekman \& Friesen, 1982) to familiarize the assistants with the process and to minimize error variance caused by observer heterogeneity.

The field study was conducted during regular business hours by teams of three research assistants over the course of three months. Two research assistants independently rated the intensity and authenticity of employees' emotional displays (inter-coder reliability $=0.78$ and 0.84 , respectively) after unobtrusively observing customer-employee dyadic interactions. The third research assistant interviewed the customers after they exited the store. We used RA rather than customer ratings of authenticity for several reasons. Following Pugh (2001), unobtrusive observations were made to reduce the possibility of sensitizing the employees under direct observation, and to minimize disturbance to other customers and employees. We use independent coders' ratings on intensity and authenticity rather than the customers' retrospective evaluations of employees' emotional expressions so as to capture emotional expressions at the time of the display rather than when the interaction was over. In addition, using research assistants rather than customers to assess authenticity and intensity reduces errors from common method bias. Finally, previous research indicates people are reasonably accurate at detecting real from fake expressions (Ekman \& Friesen, 1982; Ekman et al., 1988, 1999), which suggests different observers should have similar perceptions of authenticity, and that RA ratings are an acceptable proxy for customer ratings in this context. ${ }^{1}$

Three-hundred and twenty-six transactions with 122 service employees were observed. A customer response rate of $63 \%$ resulted in 208 sets of coding sheets and customer surveys. Seven pairs had extensive missing data. The effective sample was, therefore, 201 customer-employee dyads (customer sample: $M_{\text {age }}=30.4,18$ to $79 ; 47 \%$ female; employee sample: $M_{\text {age }}=28.2,18$ to $66 ; 56 \%$ female). The customers' demographics were self-reported, and the research assistants estimated the employees' information.

\section{Measures}

Employees' emotional displays of intensity and authenticity. In line with previous research, we conceptualized intensity in a reflective manner and

\footnotetext{
${ }^{1}$ A supplementary study revealed that RAs' and customers' ratings of employee authenticity are significantly correlated, and that using RA ratings is a more conservative test of our hypotheses.
}

measured the intensity of emotional displays with two items that assess the strength and frequency of employees' smiling (Barger \& Grandey, 2006; HennigThurau et al., 2006). See Table 1 for the measures. Two research assistants independently rated smile strength on a scale of $0-100 \%$ in $20 \%$ increments, with anchors at $0 \%$ (no smile) and 100\% (maximal smile); the frequency of smiles was measured by smiles per minute: $1=$ Not smiling at all, $2=$ Less than 1 smile per minute, $3=1-2$ smiles per minute, $4=3-4$ smiles per minute, $5=5$ or more smiles per minute, and $6=$ continuous smiling. We used four items or both coders' ratings of smile strength and the frequency as indicators because using coders' average ratings would have given display intensity only two indicators, which can lead to an under-identified model. Cronbach's $\alpha$ for the intensity scale was 0.88 .

Employees' authenticity has been measured by coders' or customers' perceived authenticity (Grandey et al., 2005; Hennig-Thurau et al., 2006) and by an assessment of employees' alternative acting strategies (Chi et al., 2011). We use the former method in this field study and adopt the latter approach in the laboratory experiment. In the field test, we assessed authenticity using coders' ratings on a three-item, seven-point scale $(1=$ "strongly disagree" to $7=$ "strongly agree") adapted from Grandey et al. (2005): "The employee faked how he felt in this interaction"; "This service provider seemed to put on an act in this interaction"; "the service provider actually experienced the emotions (s)he had to show to the customer." The authenticity scores were the average of the two coders' ratings. Cronbach's $\alpha$ for this scale was 0.95 .

Customers' epistemic motivation. In this study, we measured customers' epistemic motivation by assessing their motivation to process employees' emotional displays accurately. Following Coté and Hideg (2011), we created a three-item scale to measure customers' motivation to process employees' affective displays: "I paid attention to the service provider's emotional display"; "I was interested in the employee's emotional expressions"; "I paid close attention to employees' gestures when talking to them" ( 1 = "strongly disagree" to 5 = "strongly agree"). These items were framed in the context of customeremployee interactions in service transactions. Cronbach's $\alpha$ for this scale was 0.83 .

Customers' affective reactions to service experience. As in previous research, affective reactions were measured using items that assessed emotional reactions (Van Kleef et al., 2009). The items, adapted from Tsai and Huang (2002) and Hennig-Thurau et al. (2006), were on a five-point Likert scale ( $1=$ strongly 
TABLE 1

Results of the Confirmatory Factor Analysis in the Field Study: Study 1

\begin{tabular}{|c|c|c|}
\hline Items & Standardized Loadings & $S E$ \\
\hline \multicolumn{3}{|l|}{ Display Intensity (Adapted from Barger \& Grandey, 2006; Hennig-Thurau et al., 2006) } \\
\hline 1. The intensity of smiles (coder1/coder2) & $0.85 / 0.86$ & $0.04 / 0.04$ \\
\hline 2. The frequency of smiling (coder1/coder2) & $0.81 / 0.73$ & $0.05 / 0.08$ \\
\hline \multicolumn{3}{|l|}{ Display Authenticity (Adapted from Grandey, 2003; Grandey et al., 2005) } \\
\hline 1. This service provider seemed to be faking how he/she felt in this interaction. & 0.98 & 0.01 \\
\hline 2. This service provider seemed to put on act in this interaction. & 0.98 & 0.01 \\
\hline 3. The service provider actually experiences the emotions he had to display to the customer. & 0.99 & 0.00 \\
\hline \multicolumn{3}{|l|}{ Affective Reactions (Adapted from Hennig-Thurau et al., 2006; Tsai \& Huang, 2002) } \\
\hline 1. I felt contented after the service transaction. & 0.82 & 0.02 \\
\hline \multirow[t]{2}{*}{ 2. I felt pleased after the service transaction. } & 0.88 & 0.05 \\
\hline & & 0.021 \\
\hline 3. I enjoyed interacting with this employee. & 0.63 & 0.05 \\
\hline \multicolumn{3}{|l|}{$\begin{array}{l}\text { Cognitive Appraisals of Employee Service Performance (Adapted from Brady \& Cronin, } \\
\text { 2001, Liao \& Chuang, 2007) }\end{array}$} \\
\hline 1. I'd say the quality of my interaction with this employee is excellent. & 0.87 & 0.04 \\
\hline 2. This service employee was willing and able to provide the service I need. & 0.79 & 0.04 \\
\hline 3. I'd say that the quality of my interaction with this employee is high. & 0.84 & 0.05 \\
\hline \multicolumn{3}{|l|}{ Customers' Epistemic Motivation (Based on Coté \& Hideg, 2011) } \\
\hline 1. I was interested in the employee's emotional expressions. & 0.68 & 0.06 \\
\hline 2. I paid attention to the employee's emotional display. & 0.79 & 0.07 \\
\hline 3. I paid close attention to the employees' gestures when talking to them. & 0.71 & 0.07 \\
\hline \multicolumn{3}{|l|}{ Customer Loyalty Intentions (Adapted from Hennig-Thurau et al., 2006) } \\
\hline 1. The next time I need similar type of services, I will choose this service provider again. & 0.85 & 0.04 \\
\hline 2. I will say positive things about this service provider to others. & 0.94 & 0.01 \\
\hline 3. I will recommend this service provider to others. & 0.96 & 0.02 \\
\hline
\end{tabular}

disagree, 5 = strongly agree) and include: "I feel contented after the service transaction"; "I feel pleased after the service transaction"; "I enjoyed interacting with this employee." Cronbach's $\alpha$ for this scale was 0.82 .

Customers' cognitive appraisals of employee service performance. Customers' cognitive appraisals of the employee's service performance were measured by customers' assessment of the employee's helpfulness (one item adapted from the service performance scale, Liao \& Chuang, 2007) and their interactive experience with the service employee (two items adapted from the interaction quality scale, Brady \& Cronin, 2001). These two facets of employee service performance were chosen because they are closely linked to employees' affective delivery, whereas other dimensions of customers' cognitive appraisals, such as reliability, are more dependent on employees' taskbased service delivery (Brady \& Cronin, 2001; Tsai \& Huang, 2002). The three-item, five-point Likert scale ( 1 = strongly disagree, 5 = strongly agree) includes the following items: "I'd say the quality of my interaction with this employee is high"; "This service employee was willing and able to provide the service I need"; "I'd say the quality of my interaction with this employee is excellent." Cronbach's $\alpha$ was 0.90 .

Customer loyalty intentions. We adapted the customer loyalty intention scale from Groth et al. (2009). The items in this five-point Likert scale ( $1=$ strongly disagree, $5=$ strongly agree) are: "The next time I need a similar type of service, I will choose this service provider again"; "I will say positive things about this service provider to others"; "I will recommend this service provider to others." Cronbach's $\alpha$ for this scale was 0.94 .

\section{Preliminary Analyses}

Given the nested structure of our data (201 customer surveys from interactions with 122 employees at 36 stores), we evaluated the factor structure of the measures through a multilevel confirmatory factor analysis (MCFA) of the latent variables in our model: display intensity, display authenticity, affective reactions, cognitive appraisals, epistemic motivation, and loyalty intentions. The standardized loadings in the measurement model are high and load on their respective factors (see Table 1). The hypothesized six-factor model, where individual scale items 
loaded on separate first-order latent factors, displayed good fit $\left(\chi^{2}(137)=185.57\right.$; RMSEA $=0.04$; $\mathrm{SRMR}=0.04$; CFI = 0.98; Hu \& Bentler, 1999).

To rule out the possibility that common method bias accounts for these results, we tested an alternative two-factor model that included one latent factor composed of those items rated by research assistants (the intensity and authenticity of employees' affective displays) and a second factor based on the variables that were rated by customers (affective reactions, cognitive appraisals, epistemic motivation, and loyalty intentions). The fit of this model was poor $\chi^{2}(151)=792.41$; RMSEA $=0.15$; SRMR $=$ 0.14 ; $\mathrm{CFI}=0.75$ ) and was significantly worse than that of the first model $\left(\Delta \chi^{2}(14)=606.84, p<0.01\right)$. We also conducted two MCFAs to directly assess the distinctiveness of display intensity and display authenticity $\left(\chi^{2}(13)=22.73\right.$; RMSEA $=0.06$; SRMR $=$ $0.05 ; \mathrm{CFI}=0.98)$ and between affective reactions and cognitive appraisals $\left(\chi^{2}(8)=12.24\right.$; RMSEA $=0.05$; SRMR $=0.04$; CFI $=0.99$ ). In both cases, the twofactor model provides a good fit to the data, thereby increasing our confidence in the distinctiveness of these constructs.

\section{Hypotheses Testing}

The means, standard deviations, reliability estimates, and correlations of the variables are shown in Table 2. We predicted that the intensity of employees' positive affective displays indirectly impacts customer loyalty intentions by evoking positive affective responses in customers (as predicted by Hypothesis 1 and Hypothesis 3), whereas the authenticity of employees' positive affective displays enhances customer loyalty intentions by changing customers' appraisals of employee service performance (as predicted by Hypothesis 2 and Hypothesis 4). Further, we predicted in Hypothesis 5 and Hypothesis 6 that the indirect effects of intensity and authenticity on customer loyalty intentions are conditional on customers' epistemic motivation.

We tested these hypotheses with multilevel structural equation modeling (MSEM) using Mplus 7 (Muthén \& Muthén, 2012). MSEM enabled us to isolate the customer-level effects of interest and avoid inaccurate standard errors or biased estimation due to non-independent observations (Muthén \& Asparouhov, 2011; Preacher, Zyphur, \& Zhang, 2010). We used all scale items as indicators for the intensity and authenticity of employees' affective displays and customers' future loyalty intentions. Following recommendations for testing structural equation models including latent variable interactions, we modeled the latent factors for affective reactions, cognitive appraisals, and epistemic motivation using standardized scale scores as single indicators (Cortina, Chen, \& Dunlap, 2001). Employees within stores were the two clustering variables. We used the recommended analysis approach (Complex and Twolevel in Mplus), which computes standard errors and $\chi^{2}$ statistics taking into account nonindependence of observations due to both cluster levels (Muthén \& Muthén, 2012). We employed robust maximum likelihood estimation (MLR), which provides estimates of standard errors and $\chi^{2}$ test of model fit that controls for the nested nature of data. The resulting model provided good fit to the data $\chi^{2}(83)=151.06$; RMSEA $=0.06 ;$ SRMR $=0.10$; $\mathrm{CFI}=0.96$ ).

The results support our hypotheses. For display intensity, the direct effects indicate that employees' emotional display intensity positively relates to customers' affective reactions ${ }^{2}(b=0.13, p<0.05)$, supporting Hypothesis 1. Additionally, in line with Hypothesis 3, customers' affective reactions positively predicted their loyalty intentions $(b=0.39$, $p<0.01$ ). For display authenticity, the effect of authenticity on customers' appraisals of employee service performance was significant $(b=0.14, p<$ 0.05), in support of Hypothesis 2. The effect of appraisals on customer loyalty intentions was also significant $(b=0.51, p<0.01)$, supporting Hypothesis 4 . However, these results should be evaluated in light of the conditional indirect effects. Hypotheses 5 and 6 predict that the indirect effects of intensity and authenticity on customer loyalty intentions depend upon the customer's epistemic motivation. The results support these predictions. The interaction of affective reactions and epistemic motivation on customer loyalty intentions was negative and significant ( $b=-0.23, p<0.05$ ), whereas the interaction effect of cognitive appraisal and epistemic motivation was positive and significant $(b=0.28, p<0.01)$.

We tested the significance of the indirect effects using bias-corrected bootstrapping confidence intervals (CI) $(10,000$ re-samples), which does not require any assumptions about the sampling distribution underlying the moderated mediation model (Preacher \& Hayes, 2008). As predicted, the indirect path of

\footnotetext{
${ }^{2}$ In supplementary analyses, we also tested the effects of the intensity X authenticity interaction on customers' affective reactions and cognitive appraisals. Neither of these interactions was significant $(b=0.02$ and 0.01 , respectively; $p>0.10$ ).
} 
TABLE 2

Descriptive Statistics, Correlations, and Reliabilities for All Measures in Study $1^{\text {a }}$

\begin{tabular}{lccccccccc}
\hline \multicolumn{1}{c}{ Variables } & Mean & SD & $\mathbf{1}$ & $\mathbf{2}$ & $\mathbf{3}$ & $\mathbf{4}$ & $\mathbf{5}$ & $\mathbf{6}$ \\
\hline 1. Display Intensity & 2.66 & 1.25 & $(0.88)$ & & & & & \\
2. Display Authenticity & 3.08 & 1.98 & $0.31^{* *}$ & $(0.95)$ & & & \\
3. Affective reactions & 3.81 & 1.02 & $0.24^{* *}$ & $0.23^{* *}$ & $(0.82)$ & & \\
4. Cognitive appraisals of employee service performance & 4.04 & 0.98 & $0.19^{*}$ & $0.29^{* *}$ & $0.65^{* *}$ & $(0.90)$ & & \\
5. Customers' epistemic motivation & 2.68 & 1.06 & -0.08 & 0.13 & 0.04 & -0.09 & $(0.83)$ & \\
6. Customer loyalty intentions & 3.98 & 1.12 & $0.21^{* *}$ & $0.26^{* *}$ & $0.65^{* *}$ & $0.78^{* *}$ & -0.07 & $(0.94)$ \\
\hline
\end{tabular}

${ }^{\text {a }} n=201$

$* p<0.05$

${ }^{* *} p<0.01$

Note: Internal reliabilities (Cronbach's alphas) for the constructs are provided in parentheses on the diagonal.

intensity on customer loyalty intentions through customers' affective reactions is significant for customers with low epistemic motivation (effect $=$ $0.14, S E=0.08,90 \%$ CI $=0.01,0.24$ ), but not for customers with high epistemic motivation (effect $=$ $0.04, S E=0.03,90 \% \mathrm{CI}=0.00,0.10$ ). The indirect path of authenticity on customer loyalty intentions through appraisals of employee service performance was significant for customers with high epistemic motivation (effect $=0.21, S E=0.09,90 \% \mathrm{CI}=0.07$, 0.37), but not for customers with low epistemic motivation (effect $=0.06, S E=0.04,90 \% \mathrm{CI}=-0.01,0.15$ ).

We also probed the significant interactions with the simple effects approach, and plotted the intensity $\mathrm{X}$ motivation and authenticity $\mathrm{X}$ motivation interactions using +/ $1 S D$ of the predictor and moderator variables (Preacher, Curran, \& Bauer, 2006). As shown in Figure 2, the effects of intensity and authenticity on customer loyalty intentions were in the predicted directions. That is, the effect of intensity on loyalty intentions was greater for customers with low (versus high) epistemic motivation, while the effect of authenticity was greater for customers with high (versus low) epistemic motivation.

\section{Discussion}

Study 1 extends prior research on the impact of employees' positive affective displays on customer reactions by distinguishing between the effects of intensity and authenticity and how they influence affective reactions and cognitive appraisals. We find support for the hypothesis that intensity and authenticity affect loyalty intentions via different pathways, i.e., affective reactions and cognitive appraisals, respectively. Additionally, we find that the impact of intensity and authenticity on customer outcomes largely depends on customers' epistemic motivation.
When customers have low motivation to develop an accurate understanding of employees' positive affective displays, display intensity enhances customer loyalty intentions. When customers have high motivation to interpret employees' displayed emotions, display authenticity enhances intentions to stay loyal to the service provider. These results shed light on the different ways in which affective displays influence customer reactions, and suggest customers respond in distinct, yet predictable, ways to display intensity and authenticity depending on their epistemic motivation.

This field study is an important first step in creating a greater understanding of the relationship between employee emotional displays and customer reactions. However, this approach is not without its limitations. First, although in-situ interviews from the field study contribute to external validity, we do not have control of certain situational influences, such as the dynamics of employee-customer interactions, distractions by other employees or customers, and ambient conditions (e.g., noise, odor). Second, surveys do not enable us to establish causal relationships among constructs. To address these concerns, we conducted a well-controlled, video-simulated laboratory experiment to supplement the field study and provide convergent evidence for our hypotheses.

\section{STUDY 2: EXPERIMENT WITH MEASURED EPISTEMIC MOTIVATION}

In Study 2, we attempt to replicate our findings from Study 1 by showing all participants the same recorded service interaction and measuring epistemic motivation with a well-established measure-the 11-item need for structure scale (Neuberg \& Newsom, 1993). The personal need for structural scale is a reliable measure of individual differences in information processing motivation (Van Kleef et al., 2010). This 
FIGURE 2

\section{Interaction Effects of Display Dimensions and Motivation on Customer Loyalty Intentions}

Panel A: Moderating effect of epistemic motivation on the relationship between display intensity and customer loyalty intentions

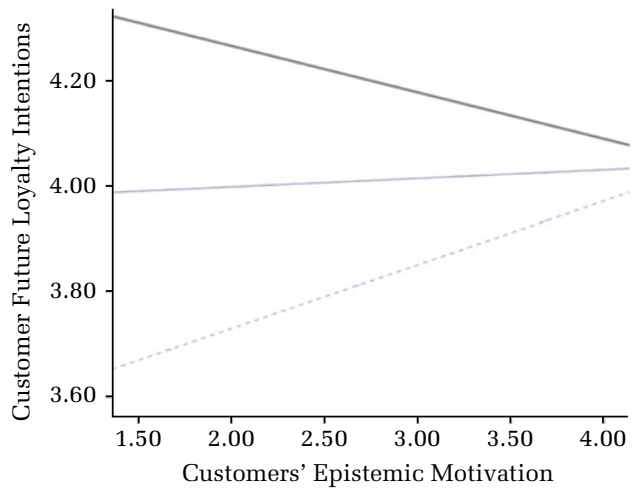

Panel B: Moderating effect of epistemic motivation on the relationship between display authenticity and customer loyalty intentions

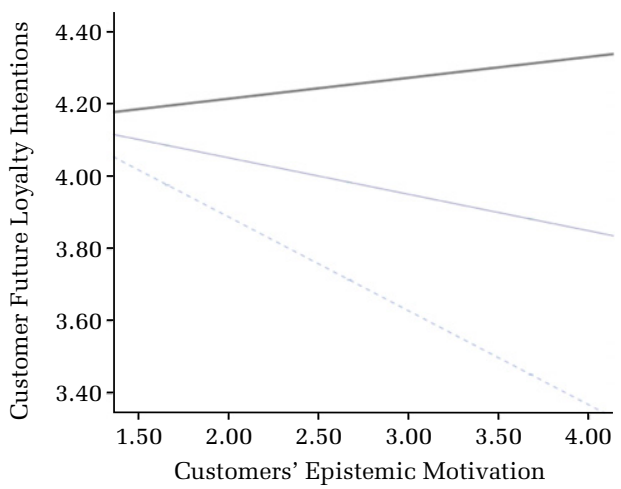

Panel A: Moderating effect of epistemic motivation on the relationship between display intensity and customer loyalty intentions. Panel B: Moderating effect of epistemic motivation on the relationship between display authenticity and customer loyalty intentions

laboratory replication is motivated by two purposes. Complementary studies with different research approaches can overcome weaknesses of one research method. Compared to Study 1, the laboratory experiment enhances internal validity by controlling potential confounding factors (e.g., ambient conditions, store busyness). Further, measuring epistemic motivation with the need for structure scale allows us to cross-validate our findings (Lykken, 1968).

\section{Experiment Preparation}

Video production. We used videotaped service interactions as stimuli because of the flexibility and realism that videotapes offer in managing manipulations and controlling confounds (Grandey et al., 2005). We recruited six female actors from a pool of part-time employees of local stores that agreed to allow filming on their premises. After initial auditions, two actors were selected. They practiced for three weeks to operationalize various experimental conditions. We assessed the actors on the basis of their acting skills and their comfort levels for performing deep acting and surface acting strategies (Hennig-Thurau et al., 2006). Based on these screenings, one actor was chosen to act as the service employee, and the other actor as the customer. The practice videos were taken and pretested for multiple rounds until the actors and experimenters were satisfied with the performance. Final versions of the 
videos were filmed in situ in a local store. All videos were professionally produced. They were approximately the same length (two and a half minutes) and had similar levels of interpersonal contact. To minimize the influence of on-screen customers on the audience's perceptions, the customers could be seen only from the back. The scripts and scenes were edited to be identical across conditions.

Manipulation of employees' emotional intensity and authenticity. The actor who played the role of the employee displayed a smile, as defined by a noticeable upward twist of the lips (Barger \& Grandey, 2006). To manipulate intensity, the actor: (a) used voice intonation, gesticulated, and showed broad and frequent smiles in the high-intensity conditions; and (b) spoke calmly, avoided gesticulating, and displayed slight and less frequent smiles in the lowintensity conditions.

Following Hennig-Thurau et al. (2006), we operationalized authenticity by training the actor in deep and surface acting techniques. When employees use "deep acting" strategies, they modify their internal feelings to match the displayed emotion, leading to authentic affective displays; when they use "surface acting" strategies, they fake manifest expressions and suppress felt emotions, resulting in inauthentic emotional expressions (Grandey, 2003). The training included reading pertinent materials (e.g., Hochschild, 1983), discussing the concepts of emotional labor, and practicing acting strategies. For example, the actor was trained in deep acting to engender genuine positive inner feelings and displays, and she used Stanislavski's (1965) acting technique to recall pleasant emotional memories and think of the upcoming customer encounters as an opportunity to help someone and make her feel good.

Pretest. We conducted a pretest to ascertain that intended authenticity and intensity levels were successfully manipulated in the videos. A total of 131 participants were randomly assigned to watch one of four experimental videos and to rate the authenticity and intensity of the employees' displayed emotions. We adopted the same scale for perceived intensity and authenticity used in Study 1 . The authenticity manipulation was successful $\left(M_{\text {auth }}=\right.$ $\left.2.64, M_{\text {inauth }}=1.63 ; F(1,127)=44.09, p<0.01\right)$. The intensity manipulation did not influence perceived authenticity. The intensity manipulation was similarly successful $\left(M_{\text {high }}=3.09, M_{\text {low }}=2.07 ; F(1,127)=\right.$ $142.36, p<0.01)$. However, the authenticity manipulation also had an effect on perceived display intensity $\left(M_{\text {auth }}=3.30, M_{\text {inauth }}=2.69 ; F(1,127)=15.73, p<\right.$ 0.01), suggesting authentic displays of positive affect appear more intense than inauthentic displays of positive affect. Previous research has also observed this spill-over impact of authenticity manipulation on intensity (see Hennig-Thurau et al., 2006). Importantly, as in past research, the intended intensity manipulation had a significantly greater effect on perceived intensity $\left(\eta^{2}=0.53\right)$ than the unintended authenticity manipulation $\left(\eta^{2}=0.11\right)$. This large difference in effect size supports the validity of the manipulation.

\section{Participants and Procedure for the Main Experiment}

Participants in this study were recruited from an online research panel $(N=343,51 \%$ female, $18-75$ years of age, $\mathrm{M}_{\text {age }}=34.2, S D=12.0$ ). Participants were randomly assigned to conditions in a 2 (display authenticity: authentic vs. inauthentic) $\times 2$ (display intensity: high vs. low) between-subjects design. They watched the service encounter video from the perspective of the customer in the scene. Immediately after watching the video, participants completed a questionnaire containing the dependent measures and ancillary questions (e.g., demographics).

Measurement of customers' epistemic motivation. Customers' epistemic motivation was measured by the 11-item need for structure scale (Neuberg \& Newsom, 1993). Prior research has validated this scale's ability to assess individuals' chronic levels of motivation to engage in systematic information processing (Van Kleef et al., 2009). Sample items from this scale include: "I enjoy having a clear and structured mode of life"; "It upsets me to go into a situation without knowing what I can expect from it." Participants in our study indicated how much they agree with each statement on a scale ranging from 1 = "strongly disagree," to $7=$ "strongly agree" $(\alpha=0.89)$.

Measurement of customers' responses. We used the same scales from Study 1 to measure customer's affective reactions $(\alpha=0.86)$ and loyalty intentions $(\alpha=0.97)$. Similar to Study 1 , we measured customers' cognitive appraisals about employee service performance using a three-item scale. The scale items include: "This service employee was willing and able to provide the service I need;" "the employee kept the best interests of the customer in mind;" "the employee seemed to achieve his/her own goals by satisfying me." The first item was from Study 1, the second and third items were adopted from Groth et al. (2009). We adopted the latter two items for this study as they specifically assess customers' appraisals of employees' behaviors and service performance. In addition, we measured customers' 
assessment of display intensity and display authenticity using the same scale items as in Study 1.

\section{Results and Discussions}

To test stage-two moderated mediation as outlined in our theoretical diagram, we again used structural equation modeling with Mplus (Muthén \& Muthén, 2012). Similar to Study 1, latent factors (affective reactions, cognitive appraisals, epistemic motivation) and their interactions were modeled using standardized scale scores following recommended procedures by Cortina et al. (2001). We used all three items as indicators for customers' future loyalty intention. The means, standard deviations, and correlation matrices of customer response variables are presented in Table 3. The model had good fit to the data $\left(\chi^{2}(24)=\right.$ 50.91; RMSEA $=0.06$; SRMR $=0.04$; CFI $=0.99$ ). In general, the results were consistent with our hypotheses. Intensity had a positive effect on customers' affective reactions ( $b=0.06, p=0.10$ ), although this relationship did not reach standard levels of significance. Authenticity also positively predicted customers' cognitive appraisals $(b=0.30, p<0.01$ ). Thus, Hypothesis 1 and Hypothesis 2 were supported. Customers' positive affective reactions $(b=$ $0.50, p<0.01)$ and favorable cognitive appraisals ( $b=0.44, p<0.01$ ) further enhanced their loyalty intentions, supporting Hypothesis 3 and Hypothesis 4. Moreover, in line with Hypothesis 5 and Hypothesis 6, findings revealed significant two-way interactions of affective reactions $\mathrm{X}$ epistemic motivation $(b=-0.09$, $p<0.05$ ) and cognitive appraisals $\mathrm{X}$ epistemic motivation on loyalty intentions $(b=0.09, p<0.05){ }^{3}$

Similar to Study 1, we used a bootstrapping-based approach with 10,000 samples to estimate the indirect effects (Preacher \& Hayes, 2008). The indirect effect of intensity on loyalty intentions via affective reactions was weaker for customers with high epistemic motivation (effect $=0.09,90 \%$ CI $=0.00$,

\footnotetext{
${ }^{3}$ We also conducted supplemental analyses in which we use the measured versions of the intensity and authenticity variables. Similar patterns of results were observed. Intensity positively predicted customers' affective reactions $(b=0.16, p<0.01$ ), authenticity positively influenced customers' cognitive appraisals $(b=0.32, p<$ 0.01). Affective reactions $(b=0.49, p<0.01)$ and cognitive appraisals $(b=0.45, p<0.01)$ enhanced customer loyalty intentions. Epistemic motivation moderated such effects as both affective reactions $\mathrm{X}$ epistemic motivation $(b=$ -0.09, $p<0.05$ ) and cognitive appraisals $\mathrm{X}$ epistemic motivation ( $b=0.10, p<0.05$ ) were significant.
}

0.22) than for customers with low epistemic motivation (effect $=0.14,90 \% \mathrm{CI}=0.00,0.30$ ). The indirect effect of authenticity on loyalty intentions as mediated by appraisals of employee service performance was stronger for customers with higher epistemic motivation (effect $=0.62,90 \%$ CI $=0.41$, 0.87 ) than for customers with lower epistemic motivation (effect $=0.40,90 \% \mathrm{CI}=0.24,0.61$ ).

This study provides further support for our proposed theoretical paradigm. In this experimental study, as well as the field study, we measured customers' epistemic motivation and provided evidence for its role in moderating the relationship between employees' affective displays and customers' responses.

\section{GENERAL DISCUSSION}

The current research was conducted to better understand the effects of two dimensions of employees' positive affective displays-intensity and authenticity-in service contexts. One field study and one laboratory experiment were conducted to test our theoretical framework, which utilized and extended the EASI model of emotion communication. The results consistently demonstrated that: (1) affective display intensity primarily influences customer outcomes through affective reactions while authenticity does so mainly through cognitive appraisals; and (2) the impact of employees' affective display intensity and authenticity on customer outcomes varies as a function of the customer's epistemic motivation. In other words, employees' display intensity enhances loyalty intentions through customers' affective reactions, especially for customers with low epistemic motivation. Employees' display authenticity affects loyalty intentions through customers' appraisals about employee service performance, and this pathway is more influential for customers with high epistemic motivation. Next, we consider the implications of these findings for research and practice.

\section{Implications for Research}

Our EASI-based model clarifies the distinct roles of authenticity and intensity in influencing customer responses and contributes to the literature on the effectiveness of employees' affective displays. Our research provides an overarching framework for understanding the influence of different dimensions of employees' emotional displays on customer responses. Further, this framework is consistent with and enhances the understanding of previous research. 
TABLE 3

Descriptive Statistics, Correlations, and Reliabilities for All Measures in Study $2^{\text {a }}$

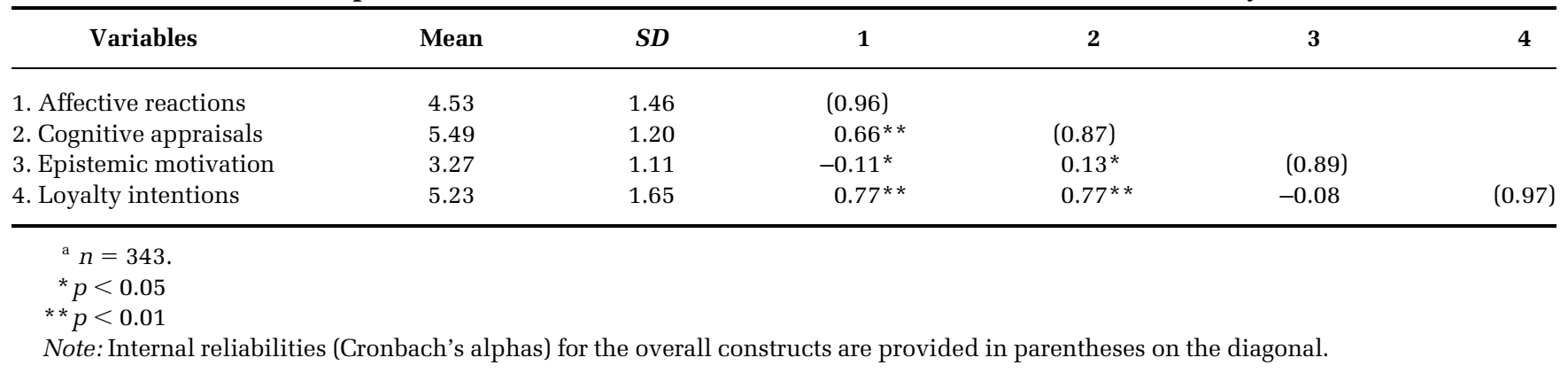

Below we discuss our results in the context of this previous work, consider the implications of our research in this context, and identify future research directions.

Although extant literature has highlighted the importance of both intensity and authenticity of employees' positive affective displays in service delivery, most studies have not distinguished between these two dimensions or have focused on one dimension without measuring the other. Several papers concluded that all smiles are "not created equal" or that "service with a smile" is not enough (Grandey et al., 2005; HennigThurau et al., 2006), yet the ways in which different types of positive emotional expressions affect observers have not been explicated. For some customers, "service with a smile" may be the best strategy while, for others only authentic positive expressions will do. In the current research, we propose a theoretical framework that can elucidate which customers respond better to intense versus authentic displays, and why.

We know of only one paper (Hennig-Thurau et al., 2006) that has explored the simultaneous roles of display intensity and authenticity. Hennig-Thurau et al. (2006) showed that after accounting for the effects of authenticity, the effects of intensity are no longer significant. They conclude authenticity is the driving force influencing customer responses to employees' emotional displays. We propose another possibility-that both dimensions of display influence customer responses, but in different situations and through different mechanisms. Indeed, their research context-a movie consulting service-was described as a personalized service in which participants would answer a series of questions about their movie-viewing habits and preferences in a one-to-one consultation. This type of service is likely to be perceived as highly personally involving, thereby increasing customers' epistemic motivation (Van Kleef et al., 2009). Their findings are consistent with our EASI-based model, such that when customers' epistemic motivation is higher, authenticity is more influential than intensity. Our research demonstrates the importance of considering dimensions of display and the context in which they occur.

Previous findings on the positive effects of employees' emotional displays on customer reactions are also consistent with our model-and can be informed by it. For example, Wang and Groth (2014) found that the effect of authenticity was accentuated when customers had a weak relationship with the employee, or when they received highly personalized services. Gabriel, Acosta, and Grandey (2013) examined how service familiarity moderates the effectiveness of employees' positive affective displays. They found that such displays had a greater impact on customers' judgments of employee service performance when customers were relatively unfamiliar with the service. Our conceptual model and empirical findings complement and extend these findings. Both unfamiliar service contexts, which promote more accurate emotion information processing, and highly personalized services, which tend to be personally involving, should increase epistemic motivation (Van Kleef et al., 2009). If this is the case, our model suggests that employees' authentic displays are more likely to result in positive customer outcomes than intense displays in these contexts, and that this is due to heightened cognitive appraisals of employees' service performance.

In all, our model provides a general framework for understanding when and why emotional displays influence customer reactions. It offers a comprehensive and textured theoretical approach that is unique from extant work-and it provides a framework to guide future research. For example, the factors that influence epistemic motivation are rich and varied. Variations in customers' epistemic motivation arise from both individual and situational differences 
(De Dreu \& Van Kleef, 2004; Van Kleef, 2009). Thus, identifying epistemic motivation as a critical moderator opens up future research paths on both individual and situational factors that affect customer reactions to employees' emotional displays.

Our work also enriches emerging research on the EASI model. Prior studies testing the EASI model have exclusively focused on how observers react to displayers' expressions of different discrete emotions, such as anger (Van Kleef, Anastasopoulou, \& Nijstad, 2010), happiness (Van Kleef et al., 2004), and disappointment and regret (Van Kleef, De Dreu, \& Manstead, 2006). These studies did not distinguish between different dimensions of emotions, such as the intensity and authenticity of displayers' expressions. In this research, we integrate the EASI literature with research on employees' affective displays, which has considered intensity and authenticity as distinct dimensions of positive expression. In general, our findings suggest that judgments about discrete emotions as social information also apply to comparing different dimensions of a single emotion. We specifically investigated the dimensions of intensity and authenticity, but future research may identify other affective dimensions that can be studied through the lens of this model. The results of our research also support the applicability of the EASI model to employee-customer interactions, which are different from the situations examined in prior research involving shared outcomes between observers and displayers (De Dreu \& Van Kleef, 2004; Van Kleef et al., 2010).

\section{Implications for Practice}

Our research provides practical implications by illuminating which customers are most likely to respond positively to intense and authentic emotional displays. Firms invest considerable resources in training and monitoring their employees' affective displays to enhance service experience and improve customer relationships. Managers often focus on either the intensity or authenticity dimension of employees' emotional displays. For example, Chick-fil-A's "the Core Four" rule asks that employees make eye contact, speak enthusiastically, smile broadly, and engage the customer. Such behavior, although less genuine or authentic by its very nature (Gountas \& Ewing, 2003), has several benefits. Employees who are required to display intense (but not necessarily authentic) positive emotions are easier to recruit, train, and monitor than those trained to be authentic (Richard, 2006).
However, such scripted emotional displays-that some have characterized as pseudo-care "lacking the essential humane attribute of genuine care" (e.g., Lynch, 1992: 379)—may not always be desirable. For certain customers, only authentic displays of positive emotion will result in positive outcomes. While prior research supports the idea that customers generally appreciate authentic positive displays (HennigThurau et al., 2006), it is expensive and time-intensive to recruit employees who exude natural warmth, or train them to display genuine positive emotions on a consistent basis. In addition, there are some situations in which the advantage of authentic displays disappears (e.g., in busy service contexts; Grandey et al., 2005), resulting in a waste of training resources.

To make the most efficient and informed decisions about emotional display rules, managers need to understand when and why intensity and authenticity positively affect customer outcomes. Our research suggests that employees' emotional display requirements should be contingent on customers' epistemic motivation. Our study focused on epistemic motivation as a characteristic of the individual. Yet, as we note above, service context is important as well. For example, we have suggested unfamiliar services and personalized services would increase customers' epistemic motivation. Similarly, routine service encounters and services that are inherently less involving may lower customers' epistemic motivation. When customers have low epistemic motivation, emotional rules without finer-grain requirements may be better. For instance, failing to deliver positive displays can be detrimental in some contexts (e.g., McDonald's admits that it is unsustainable for the company to have $20 \%$ of customers' complaints being "unfriendly employees"), but emphasis on authenticity may be an expensive investment that goes unrewarded (e.g., customers may appreciate McDonald's employees' smiling, but are less likely to make inferences about the employees' genuineness). Further, it is sometimes difficult for managers to empower the frontline (as services are often standardized or scripted) and invest extensively on employees' genuine enthusiasm (as these positions often carry low salaries). Concrete requirements of frequent positive expressions such as Walmart's "10-foot attitude" or Chick-Fil-A's "the Core Four" would be easier to implement and monitor than the requirement of authenticity.

On the other hand, when customers have high epistemic motivation, authentic positive emotional displays are needed to maximize positive customer outcomes. In such cases, employees' genuine care 
and enthusiasm should be emphasized. Recruiting employees who are naturally high on positive emotionality or temperament (Larsen \& Ketelaar, 1991), or are adept at sustaining higher emotional labor through reappraisal or deep acting_adjusting both felt and expressed emotions (Gross \& John, 2003)—is recommended. For training purposes, managers may need to adjust their techniques to include empowerment or aspirations such as "the 'wow stories' of Ritz-Carlton personnel going above and beyond the call of duty that are shared globally every week" (DeRose \& Tichy, 2013). In certain service contexts, emphasizing affective intensity and the mechanical display of positive expressive behaviors may not be sufficient to produce customer loyalty. Scripted intense positive displays may even backfire under certain circumstances because high demand for frequent smiling may result in faking or inauthentic expressions that ultimately undermine customer outcomes.

\section{Limitations and Future Research}

All studies have limitations and ours are no exception. For example, in the field study, we relied on observers' coding of emotional displays. Although this is an established and conservative approach to test our propositions, with the added benefits of minimized same-source bias (Barger \& Grandey, 2006; Pugh, 2001; Tsai \& Huang, 2002), future research may benefit from directly measuring customers' perception of the emotional display to further explore its downstream consequences. We also used a context-specific measure of epistemic motivation in Study 1. This measure has the benefit of directly assessing motivation to interpret employees' emotional display, but it had not been validated as a measure of epistemic motivation. To alleviate this concern, we conducted a follow-up study in which we examined the correlation between the Study 1 measure of epistemic motivation and the commonly used measure of epistemic motivation that we employed in Study 2. The results of this follow-up demonstrate that the Study 1 measure is strongly correlated with a standard measure of epistemic motivation $(r=0.58, p<$ 0.01). These results and the consistency of the findings from the two studies give us confidence in the context-specific measure created for Study 1. In addition, laboratory experiments often suffer from low ecological validity. We designed the experiment to approximate actual service experiences while controlling for potential confounds such as employee familiarity, but such experiments nevertheless seem artificial when compared to real customer-employee interactions. Of course, one of the benefits of utilizing different methodological approaches is that the strengths of one (e.g., the richness of the field; control in the laboratory) complement the weaknesses of the other. The consistency of the results across the studies increases our confidence in the robustness of the findings.

The practical implications of our findings are qualified by two caveats. First, extant emotional labor research, including the studies reported herein, has focused on a limited assortment of employees' affective displays (e.g., smiling, greeting, thanking the customer). However, Gremler and Gwinner (2008) indicate that other aspects of employees' nonverbal behaviors, including attentive behavior (e.g., back-channel responses), imitative behavior (e.g., matching posture and voice tone), and common grounding behavior (e.g., discovering mutual interests), also merit attention. Second, although many companies can infer the extent to which their services induce high or low motivation in customers, there is no database that measures customers' epistemic motivation. Companies in service industries, such as hotels, in which extended customer contact occurs, could create their own databases that infer customers' motivation from past interactions; other firms may need to rely on situational variables (e.g., level of involvement, the duration of the transaction, service familiarity, relationship with the service provider) or past customer feedback.

It is also worth noting that findings in both studies suggest that the intensity and authenticity facets of employees' affective displays are distinctive, yet correlated ( $r=0.31$ in Study 1). Indeed, in the laboratory, the intensity manipulation influenced perceptions of authenticity. This may be due to several reasons. First, customers might infer slight smiles or infrequent expressions as simply courteous behaviors to comply with social norms, rather than the expression of genuine positive internal feelings, as smiling and other positive affective displays are considered normative in many service encounters (Pugh, 2001; Rafaeli \& Sutton, 1990). In addition, extant research on Duchenne smiles suggests that authentic smiles compared to inauthentic smiles are more likely to involve the activation of the Orbicularis oculi (the muscle group surrounding the eyes), also known as the Duchenne marker (Ekman \& Friesen, 1982). Without a certain level of smile intensity or activation of the zygomatic major muscle, it is hard for a displayer to contract the Obicularis oculi or show 
the Duchenne marker (Hess et al., 2002). Thus, our findings are consistent with observations that authentic expressions may sometimes be perceived to be more intense than inauthentic ones.

Two alternative models might also be considered. ${ }^{4}$ First, although the EASI model and previous research (van Kleef et al., 2004) indicate that epistemic motivation should act as a second-stage moderator, one might wonder if epistemic motivation influences the relationship between intensity and authenticity and affective reactions and cognitive appraisal. To explore this possibility, we conducted supplementary analyses utilizing the data from Study 1 . The results of the supplementary analyses reveal no significant first stage moderation. Further, when epistemic motivation is included as both a first-stage and second-stage moderator, the pattern of results remains unchanged. Second, it is possible that intensity influences cognitive appraisal and authenticity influences affective reactions. It is conceivable, in some contexts, that intensity directly affects cognitive appraisals and authenticity directly affects affective reactions. Future research might consider contextual variables that enhance the relationship between intensity and cognitive appraisal and between authenticity and affective reactions.

In this paper, we considered customers' epistemic motivation as individual-level differences. Future research may further examine whether situational factors may affect customers' epistemic motivation, which in turn shape the effects of display intensity and authenticity. This knowledge may provide actionable guidelines for companies to determine whether to emphasize intensity or authenticity in employee training programs. For instance, prior research has shown that one situational factor that influences epistemic motivation is power (Keltner, Gruenfeld, \& Anderson, 2003), such that high power decreases motivation while low power enhances it (De Dreu \& Van Kleef, 2004). Along this line, companies that adhere to the policy "the customer is king" are likely to benefit from employees who display intense positive emotions, whereas those whose employees assume a more powerful role (e.g., in the health care industry) may benefit more from authentic displays. Future research might also explore other contextual factors that influence epistemic motivation such as purchase involvement (Shao, Baker, \& Wagner, 2004) and time pressure (Suri \& Monroe, 2003).

\footnotetext{
${ }^{4}$ We thank the anonymous reviewers for these suggestions.
}

In addition, extant literature, including the current research, has not addressed how cultural variables influence the interplay of employee emotional displays and customer responses in service deliveries. It is possible that customers' epistemic motivation is contingent on their cultural group membership. For instance, customers should be more motivated to process emotional cues from an in-group versus an out-group employee (Young \& Hugenberg, 2010), as people perceive in-group members to be more important social sources and are more concerned about treatment from them (Correll \& Park, 2005). Norms about emotion-communication also vary across cultures. Culture-specific encoding and decoding rules may lead customers from different cultural groups to process employees' displayed emotions differently. For instance, one core personality trait of Hispanic culture is expressive sociability (Triandis, 1989). Thus, the effects of intensity may be strengthened, as positive expressions (e.g., smile and laugh) and interpersonally engaging behaviors (e.g., hugging, touching) are valued and emphasized in the Hispanic culture (Martin, Hammer, \& Bradford, 1994).

\section{Conclusion}

In conclusion, our findings support prior research that indicates that employees' affective displays are an effective tool to enhance customer experience in services. However, our conceptualization highlights the need to consider the impact of different dimensions of emotional displays on customer responses. Our studies reveal that the effectiveness of intensity and authenticity is determined by customers' epistemic motivation in different yet theoretically predictable ways. The results of this research thus contribute to theoretical knowledge about emotional labor strategies, suggest directions for future research, and provide implications and recommendations about employee training strategies for managers.

\section{REFERENCES}

Albarracin, D., \& Kumkale, G. T. 2003. Affect as information in persuasion: A model of affect identification and discounting. Journal of Personality and Social Psychology, 84: 453-469.

Albarracin, D., \& Wyer, R. S. 2001. Elaborative and nonelaborative processing of a behavior-related communication. Personality and Social Psychology Bulletin, 27: 691-705. 
American Society for Training and Development 2013. The American Society for Training and Development (ASTD) state of the industry annual report. Available at: http://www.td.org/Publications/Blogs/ ATD-Blog/2013/ASTD-Release-2013-State-of-theIndustry-Report. Accessed June 39, 2015.

Barger, P. B., \& Grandey, A. A. 2006. Service with a smile and encounter satisfaction: Emotional contagion and appraisal mechanisms. Academy of Management Journal, 49: 1229-1238.

Berry, L. L., Wall, E. A., \& Carbone, L. P. 2006. Service clues and customer assessment of the service experience: Lessons from marketing. The Academy of Management Perspectives, 20: 43-57.

Brady, M. K., \& Cronin, J. J., Jr.. 2001. Some new thoughts on conceptualizing perceived service quality: A hierarchical approach. Journal of Marketing, 65: 34-49.

Chi, N. W., Grandey, A. A., Diamond, J. A., \& Krimmel, K. R. 2011. Want a tip? Service performance as a function of emotion regulation and extraversion. The Journal of Applied Psychology, 96: 1337-1346.

Correll, J., \& Park, B. 2005. A model of the ingroup as a social resource. Personality and Social Psychology Review, 9: 341-359.

Cortina, J. M., Chen, G., \& Dunlap, W. P. 2001. Testing interaction effects in LISREL: Examination and illustration of available procedures. Organizational Research Methods, 4: 324-360.

Coté, S. 2005. A social interaction model of the effects of emotion regulation on work strain. Academy of Management Review, 30: 509-530.

Coté, S., \& Hideg, I. 2011. The ability to influence others via emotion displays: A new dimension of emotional intelligence. Organizational Psychology Review, 1: 53-71.

DeRose, C., \& Tichy, N. 2013. How about some "happy" with that happy meal. Forbes, 23 April.

De Dreu, C. K. W., \& Van Kleef, G. A. 2004. The influence of power on the information search, impression formation, and demands in negotiation. Journal of Experimental Social Psychology, 40: 303-319.

Ekman, P. 1993. Facial expression and emotion. The American Psychologist, 48: 384-392.

Ekman, P., \& Friesen, W. V. 1982. Felt, false, and miserable smiles. Journal of Nonverbal Behavior, 6: 238-252.

Ekman, P., Friesen, W. V., \& O’Sullivan, M. 1988. Smiles when lying. Journal of Personality and Social Psychology, 54: 414-420.

Ekman, P., O’Sullivan, M., \& Frank, M. G. 1999. A few can catch a liar. Psychological Science, 10: 263-266.

Fiske, A. P. 1992. The four elementary forms of sociality: Framework for a unified theory of social relations. Psychological Review, 99: 689-723.
Fiske, S. T., \& Neuberg, S. L. 1990. A continuum model of impression formation: From category-based to individuating processes as a function of information, motivation, and attention. Advances in Experimental Social Psychology, 23: 1-74.

Fridlund, A. J. 1992. The behavioral ecology and sociality of human faces. In M. S. Clark (Ed.), Emotion: 90-121. Newbury Park, CA: Sage.

Gabriel, A. S., Acosta, J. D., \& Grandey, A. A. 2013. The value of a smile: Does emotional performance matter more in familiar or unfamiliar exchanges? Journal of Business and Psychology, 30: 37-50.

Gountas, S., \& Ewing, M. 2003. The softer side of services: exploring the effect of sincerity and emotional contagion on satisfaction. ANZMAC 2003 Conference Proceedings.

Grandey, A. A. 2003. When “the show must go on”: Surface and deep acting as determinants of emotional exhaustion and peer-rated service delivery. Academy of Management Journal, 46: 86-96.

Grandey, A. A., Fisk, G. M., Mattila, A. S., Jansen, K. J., \& Sideman, L. A. 2005. Is "service with a smile" enough? Authenticity of positive displays during service encounters. Organizational Behavior and Human Decision Processes, 96: 38-55.

Greifeneder, R., \& Bless, H. 2007. Relying on accessible content versus accessibility experiences: The case of processing capacity. Social Cognition, 25: 853-881.

Gremler, D. D., \& Gwinner, K. P. 2008. Rapport-building behaviors used by retail employees. Journal of Retailing, 84: 308-324.

Gross, J., \& John, O. P. 2003. Individual differences in two emotion regulation processes: Implications for affect, relationships and well-being. Journal of Personality and Social Psychology, 85: 348-362.

Groth, M., Hennig-Thurau, T., \& Walsh, G. 2009. Customer reactions to emotional labor: The roles of employee acting strategies and customer detection accuracy. Academy of Management Journal, 52: 958-974.

Hatfield, E., Cacioppo, J. T., \& Rapson, R. L. 1992. Primitive emotional contagion. Review of personality and social psychology In M. S. Clark (Ed.), Emotion and social behavior, vol. 14: 151-177. Thousand Oaks, CA: Sage Publications.

Hatfield, E., Rapson, R. L., \& Le, Y. C. L. 2009. Emotional contagion and empathy. In J. Decety \& W. Ickes (Eds.), The social neuroscience of empathy: 19-30. Boston, MA: MIT Press.

Hennig-Thurau, T., Groth, M., Paul, M., \& Gremler, D. D. 2006. Are all smiles created equal? How emotional contagion and emotional labor affect service relationships. Journal of Marketing, 70: 58-73. 
Hess, U., Beaupré, M. G., \& Cheung, N. 2002. Who to whom and why-cultural differences and similarities in the function of smiles. In M. H. Abel (Ed), An empirical reflection on the smile. 187-216. Lewiston, NY: The Edwin Mellen Press.

Hochschild, A. R. 1983. The managed heart: Commercialization of human feeling. Berkeley, CA: University of California Press.

Hu, L. T., \& Bentler, P. M. 1999. Cutoff criteria for fit indexes in covariance structure analysis: Conventional criteria versus new alternatives. Structural Equation Modeling, 6: 1-55.

Huy, Q. N. 1999. Emotional capability, emotional intelligence, and radical change. Academy of Management Review, 24: 325-345.

Keh, H. T., Ren, R., Hill, S. R., \& Li, X. 2013. The beautiful, the cheerful, and the helpful: The effects of service employee attributes on customer satisfaction. Psychology and Marketing, 30: 211-226.

Keltner, D., Gruenfeld, D. H., \& Anderson, C. 2003. Power, approach, and inhibition. Psychological Review, 110: 265-284.

Kruglanski, A. W. 1989. Lay epistemics and human knowledge: Cognitive and motivational bases. New York, NY: Plenum.

Kruglanski, A. W., \& Webster, D. M. 1996. Motivated closing of the mind: "Seizing" and "freezing." Psychological Review, 103: 263-283.

Krumhuber, E., Manstead, A. S., Cosker, D., Marshall, D., Rosin, P. L., \& Kappas, A. 2007. Facial dynamics as indicators of trustworthiness and cooperative behavior. Emotion (Washington, D.C.), 7: 730-735.

Laird, J. D., \& Bresler, C. 1992. The process of emotional experience: A self-perception theory. Review of personality and social psychology In M. S. Clark (Ed.), Emotion, vol. 13: 213-234. Thousand Oaks, CA: Sage Publications.

Larsen, R. J., \& Ketelaar, T. 1991. Personality and susceptibility to positive and negative emotional states. Journal of Personality and Social Psychology, 61: 132-140.

Liao, H., \& Chuang, A. 2007. A multilevel investigation of factors influencing employee service performance and customer outcomes. Academy of Management Journal, 47: 41-58.

Lynch, J. 1992. Hear it from the heart. Managing Service Quality, 3: 379-383.

Lykken, D. T. 1968. Statistical significance in psychological research. Psychological Bulletin, 70: 151-159.

Martin, J. N., Hammer, M. R., \& Bradford, L. 1994. The influence of cultural and situational contexts on Hispanic and non-Hispanic communication competence behaviors. Communication Quarterly, 42: 160-179.
Martini, T. S., \& Busseri, M. A. 2012. Emotion regulation and relationship quality in mother-young adult child dyads. Journal of Social and Personal Relationships, 29: 185-205.

Mayseless, O., \& Kruglanski, A. W. 1987. What makes you so sure? Effects of epistemic motivations on judgmental confidence. Organizational Behavior and Human Decision Processes, 39: 162-183.

Muthén, B., \& Asparouhov, T. (2011). Beyond multilevel regression modeling: Multilevel analysis in a general latent variable framework. In J. Hox \& J. K. Roberts (Eds), Handbook of advanced multilevel analysis, 15-40. New York, NY: Taylor \& Francis.

Muthén, L. K., \& Muthén, B. O. 2012. Mplus: Statistical analysis with latent variables (Version 7). Los Angeles, CA: Muthén \& Muthén.

Neuberg, S. L., \& Newsom, J. T. 1993. Personal need for structure: Individual differences in the desire for simpler structure. Journal of Personality and Social Psychology, 65: 113-131.

Payne, S. C., \& Webber, S. S. 2006. Effects of service provider attitudes and employment status on citizenship behaviors and customers' attitudes and loyalty behavior. The Journal of Applied Psychology, 91: $365-378$.

Preacher, K. J., Curran, P. J., \& Bauer, D. J. 2006. Computational tools for probing interactions in multiple linear regression, multilevel modeling, and latent curve analysis. Journal of Educational and Behavioral Statistics, 31: 437-448.

Preacher, K. J., \& Hayes, A. F. 2008. Asymptotic and resampling strategies for assessing and comparing indirect effects in multiple mediator models. Behavior Research Methods, 40: 879-891.

Preacher, K. J., Zyphur, M. J., \& Zhang, Z. 2010. A general multilevel SEM framework for assessing multilevel mediation. Psychological Methods, 15: 209-233.

Pugh, S. D. 2001. Service with a smile: Emotional contagion in the service encounter. Academy of Management Journal, 44: 1018-1027.

Rafaeli, A., \& Sutton, R. I. 1990. Busy stores and demanding customers: How do they affect the display of positive emotion? Academy of Management Journal, 33: 623-637.

Reichheld, F. F., \& Teal, T. 2001. The loyalty effect: The hidden force behind growth, profits, and lasting value. Boston, MA: Harvard Business Press.

Richard, E. M. 2006. Applying appraisal theories of emotion to the concept of emotional labor. Dissertation Abstract International, 67, UMI No. AAT 3208194.

Rust, R. T., \& Zahorik, A. J. 1993. Customer satisfaction, customer retention, and market share. Journal of Retailing, 69: 193-215. 
Salanova, M., Agut, S., \& Peiró, J. M. 2005. Linking organizational resources and work engagement to employee performance and customer loyalty: The mediation of service climate. The Journal of Applied Psychology, 90: 1217-1227.

Shao, C. Y., Baker, J. A., \& Wagner, J. 2004. The effects of appropriateness of service contact personnel dress on customer expectations of service quality and purchase intention: The moderating influences of involvement and gender. Journal of Business Research, 57: 1164-1176.

Sinclair, R. C. 1988. Mood, categorization breadth, and performance appraisal: The effects of order of information acquisition and affective state on halo, accuracy, information retrieval, and evaluations. Organizational Behavior and Human Decision Processes, 42: 22-46.

Skinner, B. F. 1953. Science and human behavior. New York, NY: Macmillan.

Suri, R., \& Monroe, K. B. 2003. The effects of time constraints on consumers' judgments of prices and products. The Journal of Consumer Research, 30: 92-104.

Stanislavski, C. 1965. An actor prepares. New York, NY: Theatre Art Books.

Swan, J. E., \& Oliver, R. L. 1989. Postpurchase communications by consumers. Journal of Retailing, 65: 516-533.

Triandis, H. C. 1989. The self and social behavior in differing cultural contexts. Psychological Review, 96: 506-520.

Tsai, W. C., \& Huang, Y. M. 2002. Mechanisms linking employee affective delivery and customer behavioral intentions. The Journal of Applied Psychology, 87: 1001-1008.

Van Kleef, G. A. 2009. How emotions regulate social life the emotions as social information (EASI) model. Current Directions in Psychological Science, 1: 184-188.

Van Kleef, G. A., Anastasopoulou, C., \& Nijstad, B. A. 2010. Can expressions of anger enhance creativity? A test of the emotions as social information (EASI) model. Journal of Experimental Social Psychology, 46: 1042-1048.

Van Kleef, G. A., De Dreu, C. K., \& Manstead, A. S. 2004. The interpersonal effects of emotions in negotiations: a motivated information processing approach. Journal of Personality and Social Psychology, 87: 510-528.

Van Kleef, G. A., De Dreu, C. K., \& Manstead, A. S. 2006. Supplication and appeasement in conflict and negotiation: The interpersonal effects of disappointment, worry, guilt, and regret. Journal of Personality and Social Psychology, 91: 124-142.

Van Kleef, G. A., Homan, A. C., Beersma, B., Van Knippenerg, D., Van Knippenberg, B., \& Damen, F. 2009. Searing sentiment or cold calculation? The effects of leader emotional displays on team performance depend on follower epistemic motivation. Academy of Management Journal, 52: 562-580.
Wang, K. L., \& Groth, M. 2014. Buffering the negative effects of employee surface acting: The moderating role of employee-customer relationship strength and personalized services. The Journal of Applied Psychology, 99: 341-350.

Young, S. G., \& Hugenberg, K. 2010. Mere social categorization modulates identification of facial expressions of emotion. Journal of Personality and Social Psychology, 99: 964-977.

\section{$M$}

Ze Wang (ze.wang@ucf.edu) is an assistant professor of marketing at the College of Business Administration, University of Central Florida. She received her $\mathrm{PhD}$ from the University of Kansas. Her research examines customers' service experience from both customers' and firms' perspectives, particularly with respect to frontline management, impression formation, social judgments, and consumer-generated content analysis.

Surendra N. Singh (ssingh@ku.edu) is AT\&T Foundation Professor of Business, and Area Director: Marketing and Business Law, School of Business and Professor of Health Policy and Management, School of Medicine, University of Kansas.

Yexin Jessica Li (Jessica.Li@ku.edu) is an assistant professor of marketing at the School of Business, University of Kansas. She received her $\mathrm{PhD}$ from Arizona State University. Her research interests include social cognition and the role of motivations and emotions on consumer decision-making.

Sanjay Mishra (smishra@ku.edu) is associate professor of Marketing at the School of Business, University of Kansas. He received his $\mathrm{PhD}$ from Washington State University. His research focuses on consumers' response to information, e.g., new introductions, brands, web sites, environmental cues.

Maureen Ambrose (mambrose@ucf.edu) is the Gordon J. Barnett Professor of Business Ethics at the University of Central Florida. She received her $\mathrm{PhD}$ from the University of Illinois at Urbana-Champaign. Her research interests include organizational fairness, ethics, and workplace deviance.

Monica Biernat (biernat@ku.edu) is Professor of Psychology and Associate Chair at the University of Kansas where she directs the PhD program in social psychology. Her primary research examines the processes of stereotyping and prejudice, and focuses on how stereotypes affect judgments of individual members of stereotyped groups. She is currently Editor of Personality and Social Psychology Review and Executive Officer of the Society for Experimental Social Psychology.

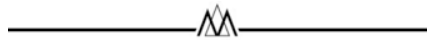


Copyright of Academy of Management Journal is the property of Academy of Management and its content may not be copied or emailed to multiple sites or posted to a listserv without the copyright holder's express written permission. However, users may print, download, or email articles for individual use. 